\title{
Confirmation of discrepancies between exercise oximetry and American Heart Association post-exercise criteria to diagnose peripheral artery disease in patients with normal ankle-brachial index at rest
}

\author{
Guillaume Mahé $^{1,2}$ (D) . Floriane Catillon ${ }^{1} \cdot$ Quentin Tollenaere $^{1} \cdot$ Olivier Stivalet $^{1} \cdot$ Antoine Guilcher $^{1} \cdot$ Estelle Le \\ Pabic $^{3}$ - Virginie Jegou ${ }^{1,3} \cdot$ Loukman Omarjee $^{1,3,4}$ - Alexis Le Faucheur ${ }^{5}$
}

Received: 13 February 2020 / Revised: 13 February 2020 / Accepted: 18 February 2020 / Published online: 27 February 2020

(C) Springer-Verlag GmbH Germany, part of Springer Nature 2020

We read with great interest the paper from Abraham and colleagues entitled "Comparison of exercise oximetry and ankle pressure measurements for patients with intermittent claudication: an observational study of 433 patients" [1]. In their original paper, the authors showed that discrepancies exist between exercise oximetry results and post-exercise ankle pressure criteria proposed by the American Heart Association (AHA). We conducted a similar study comparing exercise oximetry with post-exercise AHA tests. The validation of the AHA post-exercise criteria (post-exercise ABI decrease $>20 \%$ and/or post-exercise ankle pressure decrease > $30 \mathrm{mmHg}$ ) are discussed [6,9]. However, as Abraham and colleagues compared their results with AHA criteria [1], we also performed a similar analysis in order to see if we would obtain comparable results.

We included 96 consecutive patients with exertional limb symptoms and normal ABI at rest (versus 82 for Abraham et al.) in the exercise PAD study that was registered with the American National Institutes of Health database under reference ${ }^{\circ} \mathrm{NCT} 03186391$. The methodology of our study has been previously described [9]. In brief, patients had ABI

This article is a commentary to the original article https://doi.org/10.1007/ s00424-019-02340-w

Guillaume Mahé

maheguillaume@yahoo.fr

1 Vascular Medicine Unit, CHU Rennes, Rennes, France

2 Univ Rennes 1, INSERM CIC 1414, Rennes, France

3 CHU Rennes, Inserm, CIC 1414 (Clinical Investigation Center), F-35000 Rennes, France

4 Vascular Medicine, Hospital, Redon, France

5 Univ Rennes 2, M2S-EA 7470, F-35000 Rennes, France measurement, exercise oximetry and post-exercise pressure measurements on a same appointment to allow for comparisons between tests. ABI and post-exercise pressures were measured using hand-held Doppler for leg pressures and with an automatic device (Carescape ${ }^{\mathrm{TM}}$ Dinamap V100; GE Healthcare) for brachial pressures [8,9]. Exercise oximetry was performed as previously described by using validated in-house free software (Oxymonitor; https://imagemed.univrennes1.fr/en/oxymonitor/download.php) [5, 7].

For the statistical analyses, we analysed the concordance between exercise oximetry and post-exercise pressure decrease and post-exercise ABI decrease measured on the most symptomatic leg by using the Kappa coefficient with a confidence interval of $95 \%$ [4]. Post-exercise ABI decrease $>20 \%$, post-exercise ankle pressure decrease $>30 \mathrm{mmHg}$ and delta from rest of oxygen pressure (DROP) value equal or greater than $-15 \mathrm{mmHg}$ were considered as diagnosis for PAD as previously validated $[2,3,6,9]$.

Seventy six percent of the participants were male with a mean age of $61 \pm 13$ years. Prevalence of PAD was $44 \%, 32 \%$ and $34 \%$ using post-exercise ABI decrease, post-exercise ankle pressure decrease and exercise oximetry, respectively. Results of the concordance are presented in Table 1.The concordance between post-exercise ABI decrease and exerciseoximetry was $0.28[0.09 ; 0.48]$. The concordance between post-exercise ankle pressure decrease and exercise-oximetry was $0.30[0.10 ; 0.50]$. The concordance between post-exercise ankle pressure decrease or post-exercise ABI decrease and exercise oximetry was $0.31[0.12 ; 0.50]$.

Our results strengthen the results from Abraham and colleagues confirming that exercise tests are not equivalent. Our study has several major points of interest: 1) only patients with exertional limb symptoms and normal ABI were included, as recommended by the AHA algorithm for PAD diagnosis; 2) 
Table 1 Concordance between exercise tests

$\mathrm{PAD}+$

Exercice oximetry DROP

$\leq-15 \mathrm{mmHg}$
PAD -

Exercice oximetry DROP

$>-15 \mathrm{mmHg}$

$\mathrm{PAD}+$

Post ABI decrease $>20 \%$

$21(50 \%)$

$21(50 \%)$

Post-exercise ankle pressure decrease $>30 \mathrm{mmHg}$

$17(55 \%)$

$14(45 \%)$

Post ABI decrease $>20 \%$ or post-exercise ankle pressure decrease

$22(51 \%)$

$21(49 \%)$

PAD -

Post ABI decrease $\leq 20 \%$

$12(22 \%)$

$42(78 \%)$

Post-exercise ankle pressure decrease $\leq 30 \mathrm{mmHg}$

$16(25 \%)$

$49(75 \%)$

Post $\mathrm{ABI}$ decrease $\leq 20 \%$ and post-exercise ankle pressure decrease

$11(21 \%)$

$42(79 \%)$

$A B I$ means ankle-brachial index; $D R O P$ means delta from rest of oxygen pressure; $P A D+$ means presence of peripheral artery disease; $P A D-$ means absence of peripheral artery disease

we used validated methodology to record ABI at rest, postexercise ankle pressure [9];3) to reduce latency between end of exercise and measurement, post-exercise pressures were measured first on the symptomatic leg and the artery to perform the measurement was identified at rest as previously suggested [8]. One limitation of our study compared with Abraham et al. study is that the order of exercise oximetry and exercise pressure measurement was not randomized; however, a 15-min rest period was observed between the two tests. In conclusion, post-exercise ABI, post-exercise ankle pressure and exercise oximetry tests did not identify the same patients. The place of each test in the management of PAD remains to be studied.

Availability of data and material The data analysed during the current study are available from the corresponding author on reasonable request.

\section{Compliance with ethical standards}

Conflict of interest The authors declare that they have no conflict of interest.

\section{References}

1. Abraham P, Hersant J, Ramondou P, Picquet J, Feuilloy M, Henni S, SOCOS group (2020) Comparison of exercise oximetry and ankle pressure measurements for patients with intermittent claudication: an observational study of 433 patients. Pflugers Arch doi: https://doi. org/10.1007/s00424-019-02340-w, 1, 9

2. Abraham P, Picquet J, Vielle B, Sigaudo-Roussel D, PaisantThouveny F, Enon B, Saumet J-L (2003) Transcutaneous oxygen pressure measurements on the buttocks during exercise to detect proximal arterial ischemia: comparison with arteriography. Circulation 107:1896-1900. https://doi.org/10.1161/01.CIR. 0000060500.60646.E0

3. Koch C, Chauve E, Chaudru S, Le Faucheur A, Jaquinandi V, Mahé G (2016) Exercise transcutaneous oxygen pressure measurement has good sensitivity and specificity to detect lower extremity arterial stenosis assessed by computed tomography angiography. Medicine (Baltimore) 95:e4522. https://doi.org/10.1097/MD. 0000000000004522

4. Landis JR, Koch GG (1977) The measurement of observer agreement for categorical data. Biometrics 33:159-174

5. Mahé G, Kaladji A, Le Faucheur A, Jaquinandi V (2015) Internal iliac artery stenosis: diagnosis and how to manage it in 2015. Front Cardiovasc Med 2:33. https://doi.org/10.3389/fcvm.2015.00033

6. Mahe G, Pollak AW, Liedl DA, Cohoon KP, Mc Carter C, Rooke TW, Wennberg PW (2015) Discordant diagnosis of lower extremity peripheral artery disease using American Heart Association Postexercise Guidelines. Medicine (Baltimore) 94:e1277. https:// doi.org/10.1097/MD.0000000000001277

7. Poulin A, Guilcher A, Omarjee L, Jaquinandi V, Gandon Y, Mahe G, Stivalet O (2018) Validation of a software to perform exercise oximetry to diagnose arterial stenosis of the lower limbs. Atherosclerosis 278:325-327. https://doi.org/10.1016/j.atherosclerosis.2018.08.025

8. Stivalet O, Laneelle D, Omarjee L, Mahe G (2019) Post-exercise criteria to diagnose lower extremity peripheral artery disease: which one should I use in my practice? Vasc Med 24:76-77. https://doi.org/ 10.1177/1358863X18811932

9. Stivalet O, Paisant A, Belabbas D, Omarjee L, Le Faucheur A, Landreau P, Garlantezec R, Jaquinandi V, Liedl DA, Wennberg PW, Mahé G (2019) Exercise testing criteria to diagnose lower extremity peripheral artery disease assessed by computed-tomography angiography. PLoS One 14:e0219082. https://doi.org/10.1371/ journal.pone.0219082

Publisher's note Springer Nature remains neutral with regard to jurisdictional claims in published maps and institutional affiliations. 